\title{
Drama Adaptasi Korea: Suatu Analisis Terhadap Pemaparan Agama dan Adat dalam Drama 'Alamatnya Cinta'
}

\author{
NAZRA ALIFF NAZRI \\ ABDUL LATIFF AHMAD \\ Universiti Kebangsaan Malaysia
}

\begin{abstract}
ABSTRAK
Pada masa kini, antara jenis penghasilan drama tempatan ialah drama adaptasi yang diambil dari negara luar. Namun, progam dari luar ini dilihat mampu memberikan pengaruh yang kurang baik khususnya terhadap khalayak tempatan dan berpotensi dalam menggantikan nilai-nilai budaya yang ada. Justeru itu, kajian ini bertujuan untuk melihat bagaimana pemaparan agama dan adat tempatan diketengahkan dalam drama adaptasi dari negara Korea Selatan. Dari situ, akan diketahui tembusan dan silang budaya yang berlaku antara masyarakat Melayu dan Korea Selatan melalui penghasilan drama adaptasi ini dalam konteks tempatan. Kaedah yang digunakan dalam kajian ini adalah analisis tekstual ke atas drama 'Alamatnya Cinta' yang diadaptasi daripada siri popular Korea Selatan 'Full House' pada tahun 2018. Kaedah ini sesuai digunakan bagi mendalami mesej yang cuba disampaikan oleh pembuat teks melalui penggunaan elemen agama dan adat di dalam drama adaptasi ini. Hasil kajian mendapati walaupun drama ini merupakan sebuah drama adaptasi dari Korea Selatan namun elemen kebudayaan Melayu dan Islam itu masih banyak dipamer dan dipertontonkan kepada masyarakat. Ini sekaligus menunjukkan bahawa pembuat teks bagi drama adaptasi tempatan masih peka dan tidak memandang ringan kepada penggunaan elemen agama dan adat dalam menghasilkan sebuah naskah terutama karya adaptasi.
\end{abstract}

Keywords: Drama, adaptasi, agama, adat, analisis tekstual.

\section{Korean Adaptation Drama: An Analysis on the Portrayal of Religion and Customs in the Drama 'Alamatnya Cinta'}

\begin{abstract}
Nowadays, among the types of local drama production are adaptation dramas from foreign countries. However, the foreign programmes are considered able to give a less positive influence, especially to the local audience and may potentially replace the existing cultural values. Therefore, this study aims to understand how the portrayal of local religions and customs are featured in an adaptation drama from South Korea. From there, we may find the cross-cultural penetration that occurs between the Malay and South Korea societies through the production of this drama adaptation in the local context. The method used for this study is a qualitative approach of textual analysis on the drama 'Alamatnya Cinta' adapted from the popular South Korean series 'Full House' in 2018. Accordingly, this method is also used to find out comprehensively the messages in which the text maker is trying to deliver through the use of religious and customary elements in this adaptation drama. The study found that while this drama is a drama adaptation of South Korea but elements of Malay culture and Islam are very much exhibited and shown to the public. This also shows that the text maker for local adaptation dramas are still sensitive and do not underestimate the use of religious and customary elements in producing a script, especially in adaptation works.
\end{abstract}

Keywords: Drama, adaptation, religion, custom, textual analysis. 


\section{PENGENALAN}

Kemajuan teknologi dan budaya pada masa kini merupakan sebuah fenomena yang saling berkait rapat antara satu sama lain. Menurut Tian et al. (2018), penggunaan teknologi ini juga dikatakan mempunyai peranannya yang tersendiri dalam mempengaruhi perkembangan budaya sesebuah kelompok masyarakat. Dalam pada itu, perkara ini dilihat selari dengan apa yang diperkatakan oleh Alftberg dan Bengsten (2018), di mana budaya pada era kini sememangnya saling berkait dengan teknologi yang semakin canggih sekaligus menjadikannya sesuatu perkara yang lebih kompleks dan rumit.

Kurt dan Got (2015) juga ada menyatakan bahawa masyarakat kini tidak perlu lagi meninggalkan persekitaran mereka untuk didedahkan dengan budaya asing. Hal ini disebabkan telah wujudnya teknologi yang mampu menghilangkan sempadan antara budaya tersebut seperti televisyen, radio dan media baru. Menurut Putri (2017), televisyen adalah salah satu produk teknologi yang mampu menghasilkan visual dan bunyi serta amat berpotensi bagi mendapatkan perhatian dari seluruh masyarakat pada masa kini.

Melalui televisiyen, masyarakat akan lebih mengetahui tentang dunia dan budaya luar di samping mampu untuk mempermudahkan hubungan antara individu yang datang dari persekitaran dan budaya berbeza. Tambahnya lagi, revolusi informasi dan komunikasi yang semakin canggih ini juga dilihat mampu menembusi segala sudut ruang dan juga waktu bagi memudahkan penyampaian sesebuah teks mahupun mesej.

Namun begitu, menurut Naquiah et al. (2018), kepesatan perkembangan teknologi moden ini sebenarnya tetap memberi kesan yang amat besar seterusnya mengubah landskap kehidupan manusia sejagat tanpa mengira tahap serta peringkat usia. Rentetan daripada itu, struktur dan cara hidup manusia juga dilihat berubah sejajar dengan pembangunan teknologi yang berlaku pada masa kini (Ahmad Fauzi et al., 2014). Justeru kajian yang dilakukan ini dilihat bersesuaian sekali dengan konteks semasa iaitu memfokuskan pada bentuk pemaparan agama dan budaya yang hadir menerusi drama adaptasi Korea Selatan oleh pembuat teks.

\section{AGAMA, ADAT DAN BUDAYA POPULAR}

Agama merupakan satu bentuk kepercayaan dan pegangan hidup bagi sesiapa yang menganutinya. Selain itu, pada asasnya perkataan 'agama' (religion) berasal dari terminologi bahasa Latin berbunyi religare yang bermaksud 'untuk mengikat' (Lakonawa, 2013). Menurut Mohd Daud Ali (2002), agama adalah satu bentuk kepercayaan kepada Tuhan yang dizahirkan melalui ritual, upacara penyembahan dan permohonan dalam membentuk sikap hidup manusia berdasarkan ajaran sesebuah agama tersebut. Menurut Grondona (2000) pula, agama sangat berperanan dalam kehidupan manusia kerana berkait dengan dimensi diri bagi setiap individu. Selain agama, adat juga merupakan antara komponen yang amat penting dalam kehidupan masyarakat Melayu. Hal ini kerana pengaruh dari sudut adat dan agama dapat dilihat dalam hampir setiap aspek kehidupan masyarakat (Yusoff et al., 2013). Agama dan adat ini boleh digambarkan sebagai sebuah elemen yang saling berkait antara satu sama lain bagi mencerminkan budaya dan bangsa sesebuah komuniti.

Penggunaan aspek agama dalam pembikinan sesebuah karya adalah amat penting dalam membimbing dan memberi sumbangan ke arah kehidupan yang lebih bertamadun dan positif. Hal ini turut disokong oleh Rosmawati dan Azimah (2016) yang menyatakan bahawa pemaparan elemen Islam ini mampu mendidik masyarakat di samping bertindak sebagai sebuah medium komunikasi dalam menyampaikan maklumat. Oleh itu, penggunaan dan 
pemaparan terhadap agama khususnya Islam dalam sesebuah penghasilan karya adalah satu artifak budaya yang penting dan harus diberi perhatian yang lebih (Ngo \& Harith, 2015).

Seterusnya bagi adat pula, Nor Raudah et al. (2019) berpendapat adat merujuk kepada perlakuan dan tingkah laku yang telah diterima oleh sesebuah anggota masyarakat serta peraturan sosial yang mengandungi kod etika dan moral berlandaskan nilai-nilai sosial tempatan. Justeru itu menurut Abu Hassan Sham et.al (2001), disebabkan budaya bagi masyarakat Melayu berteraskan Islam dan adat, maka kedua-duanya menjadi asas utama dalam proses sosiologi dan pembentukan kebudayaan. Tambahan lagi, pada masa kini, dengan wujudnya media massa yang semakin moden, tidak mustahil adat daripada budaya lain turut boleh meresapi jiwa anak-anak muda pada masa kini menerusi budaya popular yang dibawa terutamanya dalam bentuk drama, filem dan juga lagu. Rentetan itu, Fatimah dan Nur Afifah (2018) menjelaskan penggunaan adat dalam sesebuah karya ini turut memberi kesan secara tidak langsung kepada audiens dalam membentuk identiti negara bangsa.

Menurut Dominic (2003), budaya popular adalah kebudayaan yang terbentuk atau dibentuk oleh media massa. Ini kerana, media massa dapat menawarkan suatu bentuk kebudayaan konsumtif dan masyarakat pengguna media mengikutinya atau menggunakan siaran televisyen sebagai preferensi kebudayaan dan gaya hidupnya. Tambahan itu, menurut Muhammad Khairul Hafiz el al. (2019), di Malaysia fenomena budaya popular merupakan suatu realiti yang tidak dapat dipisahkan dalam sistem sosial dan budaya sesebuah masyarakat disebabkan oleh peningkatan terhadap kemajuan teknologi maklumat dan komunikasi yang mendorong kepada penyaluran budaya asing secara terbuka ke dalam negara. Labas dan Mihovilovic (2011), pula menyatakan bahawa budaya popular adalah sebuah komponen penting dalam masyarakat moden masa kini yang telah diintegrasikan dan disematkan ke dalam bidang dan bahagian seperti persembahan, filem, fesyen, semua jenis seni, teknologi, reka bentuk, sukan, makanan dan juga hiburan.

Namun begitu, dengan kemasukan budaya popular secara terus ini juga dilihat mampu memberikan kesan kepada agama dan adat di Malaysia khususnya. Sebagai contoh, pada penghujung tahun 2017, dunia telah dikejutkan dengan kes kematian vokalis popular Kumpulan Korea Selatan, Shinee iaitu Kim Jonghyun yang meninggal dunia akibat membunuh diri menggunakan gas beracun. Rentetan itu di Malaysia, sebuah perhimpunan dengan kirakira 100 peminat ahli kumpulan Shinee telah berkumpul di tepi Sungai Klang dekat Masjid Jamek, Kuala Lumpur dengan membawa lilin dan juga belon sebagai tanda simbolik pemergian penyanyi kumpulan Shinee itu (Malaysia Kini, 2017).

Selain itu, pada bulan April 2019 lalu, kes yang melibatkan selebriti dari Korea Selatan di Malaysia ini masih tidak surut apabila wujudnya perdebatan besar dan kekecohan berlaku antara Pencetus Ummah Syed dengan warga netizen berkenaan dengan kemasukan ahli Kumpulan Korea Selatan, BTS ke Malaysia yang dirasakan tidak wajar dan mempunyai agenda tertentu (Astro Awani, 2019). Oleh itu, apa yang dinyatakan oleh Noriati (2005) iaitu nilai kesantunan yang ada pada orang Melayu seperti menjaga perasaan dan mengutamakan pandangan serta penerimaan masyarakat kian luntur dan semakin pudar di era globalisasi kini.

Justeru, perkara ini dilihat sealiran dengan apa yang diperkatakan Md Azalanshah (2019) iaitu populariti budaya pop daripada Korea Selatan dalam kalangan wanita Melayu kini amat membimbangkan serta cenderung untuk menghakis budaya masyarakat Melayu serta menyalahi nilai-nilai Islam yang ada di negara Malaysia. 
Dalam pada itu, dengan lambakan dan letusan budaya popular dari luar ini dilihat menjadikan masyarakat di Malaysia khususnya remaja wanita mudah terikut dengan pembawaan dan agenda yang disampaikan daripada budaya popular terutama dari luar negara ini. Ini juga dilihat selari dengan pernyataan Md Azalanshah (2019) iaitu budaya popular mempunyai peranan yang amat besar dalam kehidupan masyarakat umum khususnya wanita. Tambahan pula pada era globalisasi kini, informasi dalam bentuk apapun dapat disebarluaskan dengan mudah dan cepat sehingga mempengaruhi corak pandangan, gaya hidup, serta budaya suatu bangsa (Sohana, 2016).

\section{PENONTONAN DRAMA DI MALAYSIA}

Dari sudut pandangan drama tempatan di Malaysia, kerajaan telah cuba menggunakan budaya popular ini sebaiknya sebagai pemacu kepada 'pembinaan sesebuah negara dan juga mencapai objektif kebudayaan' (Md Syed \& Hamzah, 2012). Hal ini kerana, budaya bukan sahaja mempunyai nilai estetik sosial yang besar dan amat bermakna malah merupakan aset kemajuan kepada sesebuah negara. Namun begitu, kebanyakan drama tempatan yang ditaja oleh kerajaan masih tidak dapat menarik minat penonton kerana dilihat kekurangan dari sudut teknikal dan kreatif.

Kebanyakan rakyat di Malaysia juga masing-masing lebih memilih rancangan luar berbanding penerbitan tempatan. Hal ini selari dengan pernyataan Ilias (2011), iaitu kebanyakan masyarakat di Malaysia menonton televisyen terutamanya drama luar negara kerana hiburan. Individu yang menonton drama luar negara ini semestinya sedikit sebanyak akan mendapat idea dan pengaruh daripada rancangan barat tersebut. Tambahan dengan zaman moden kini, akses kepada rancangan luar negara melalui internet dilihat amat senang dan mudah diakses masyarakat. Selain itu, bentuk penyiaran di internet ini juga sebenarnya memberikan kepuasan yang lebih terutamanya dalam kalangan remaja disebabkan faktor kedekatan golongan ini dengan penggunaan internet (Hasrul Hashim \& Bahiyah Omar, 2011).

Antara rancangan luar yang diminati masyarakat pada masa kini datangnya dari negara Korea Selatan (Julina et al., 2018). Tambahan, populariti muzik dan drama daripada Korea Selatan juga dilihat amat ketara di Malaysia melalui bintang besar mereka yang terkenal di Malaysia dan juga kedekatan budaya yang ada di antara kedua-dua buah negara ini. Disebabkan hal ini, stesen radio dan televisyen di Malaysia telah mula untuk melanggan dan memasukkan muzik dan drama Korea Selatan ke dalam program tempatan mereka (Julina 2016). Dalam pada itu, drama-drama adaptasi daripada Korea Selatan juga sudah mula mendapat perhatian penonton di Malaysia seperti drama My Coffee Prince, Alamatnya Cinta dan juga Monalisa sehingga terciptanya sebuah slot yang memainkan drama-drama adaptasi di Astro iaitu Slot Tiara di Astro Prima.

Menurut Villano (2012), adaptasi ini merujuk amalan tekstual yang secara formal dalam membentuk teks dan menyusun semula teks pada sesuatu masa yang berbeza, budaya yang berbeza serta medium yang berbeza. Terdapat pelbagai punca dan faktor untuk menjadi dasar kepada sebuah proses adaptasi karya antaranya ialah memiliki kedekatan emosi dengan penonton, keinginan untuk melestarikan karya yang akan diadaptasi, karya yang akan diadaptasi sudah terkenal, karya tersebut mendapat tempat dan laris di pasaran (best seller) dan menarik minat masyarakat, sehingga masyarakat umum sudah tidak asing lagi dengan ceritanya. Menurut Rybina (2018), adaptasi merujuk sebuah proses transisi terjemahan kreatif yang dibuat terhadap sesebuah sumber dan mesej serta dicipta semula mengikut pentafsiran pembuat teks dengan menggunakan medium dan juga platform tertentu. 


\section{SINOPSIS DRAMA 'ALAMATNYA CINTA'}

'Alamatnya Cinta' adalah sebuah drama bersiri Malaysia pada tahun 2018 yang diadaptasi dari drama popular Korea Selatan iaitu Full House lakonan Rain dan Song Hye Kyo pada tahun 2004. Dalam ruang lingkup Malaysia, drama ini telah diarahkan oleh Bernard Chauly, Feroz Kader dan Farid Ramlee terbitan syarikat Global Station Sdn Bhd. Drama siri ini turut dibintangi dan diterajui oleh pelakon popular seperti Hannah Delisha dan juga Hisyam Hamid. Siri ini telah disiarkan serentak menerusi Slot Mega Drama di Astro Ria dan Astro Ria HD pada 20 Ogos 2018 yang lalu dengan 24 bilangan episod.

Drama ini umumnya mengisahkan kehidupan Ellie Farhana (Hannah Delisha) iaitu seorang penulis novel yang telah kehilangan rumah pusaka ayahnya apabila rumah tersebut dilelong dan dibeli oleh pelakon terkenal Malaysia iaitu Faliq Assad (Hisyam Hamid). Hal ini berlaku kerana setelah putus tunang dengan Jasmine, Faliq Assad telah mengambil keputusan untuk membeli rumah tersebut dan berpindah ke rumah baru itu bagi menenangkan fikirannya disebabkan lokasinya di pinggir kota.

Semenjak itu pelbagai kejadian berlaku antara Faliq dan Ellie terutamanya apabila skandal antara Faliq dan Ellie menjadi tular di media sosial angkara wartawan hiburan dan juga peminat setia Jasmine yang bernama Natalia. Setelah berbincang, akhirnya Emma iaitu pengurus Faliq dan juga Omar yang merupakan kawan baik Faliq telah mencadangkan supaya mereka berdua berkahwin untuk menyelamatkan kariernya dari musnah disebabkan berita kontroversi yang membabitkannya dengan Ellie.

Ellie yang pada mulanya tidak menyukai idea tersebut akhirnya bersetuju untuk berkahwin dengan Faliq, tapi dengan syarat Faliq haruslah menyiasat perihal mengapa ayahnya jatuh muflis dan dia perlu mendapatkan semula hak milik rumah pusakanya apabila tiba waktu yang sesuai. Dalam pada itu, Faliq juga turut mengenakan beberapa syarat yang Ellie perlu lakukan seperti mengemas rumah dan memasak untuknya setiap hari. Selepas berkahwin, mereka telah pergi berbulan madu kerana terpedaya dengan rancangan Omar, sejak dari itu kedua-dua mereka semakin rapat dan akhirnya jatuh hati antara satu sama lain.

\section{KAEDAH KAJIAN}

Kajian ini menggunakan kaedah kualitatif iaitu analisis tekstual yang mana penggunaannya dalam sesebuah kajian dilihat sebagai suatu dimensi baharu pada hari ini (Md Azalanshah, 2019). Menurut Ospina (2004), kaedah penyelidikan kualitatif ini penting kerana menitikberatkan penggunaan perkataan dan juga visual. Di sini, penyelidik mencari pengertian dan mengintepretasikan maksud tersebut bagi membina dan memahami pembinaan sosial yang wujud menerusi drama adaptasi ini. Kelebihan menggunakan kaedah ini adalah kerana mampu menghasilkan data yang menyeluruh dan lebih mendalam. Struppert (2006) berpendapat analisis tekstual dilihat amat berguna kerana lebih mendalam dan memberi peluang untuk mengetahui maksud yang terkandung di dalam sesebuah teks media tersebut dengan lebih luas.

Dalam kes ini, kajian ini mengenal pasti aspek yang hendak dilihat seperti keunikan dan elemen budaya khususnya Korea Selatan yang terdapat dalam sampel program televisyen yang dipilih. Menurut Kloskowska (1996), asas kepada budaya kebangsaan sesebuah negara terbahagi kepada tujuh iaitu bahasa, sastera, kesenian, agama, adat, simbol dan juga tradisi. Namun kajian ini hanya akan menfokuskan kepada dua unit sahaja iaitu agama dan juga adat kerana menurut Solahuddin (2016), agama Islam dan juga adat Melayu memberi dampak yang begitu signifikan dalam kehidupan masyarakat Melayu khususnya di Malaysia. 
Drama yang dipilih dalam kajian ini adalah 'Alamatnya Cinta' yang disiarkan pada tahun 2018 dan justifikasi pemilihan terhadap drama ini kerana rancangan berbentuk adaptasi kini amat popular dan mendapat tempat dalam kalangan masyarakat di Malaysia. Selain itu drama adaptasi 'Alamatnya Cinta' ini juga merupakan sebuah drama adaptasi Korea Selatan daripada siri asal 'Full House' yang pernah menjadi fenomena di Malaysia dan rantau asia suatu ketika dulu apabila jumlah tontonannya melebihi jangkaan yang sepatutnya (KOREA.net, 2019).

\section{ANALISIS KAJIAN}

Setelah menganalisis kesemua 24 episod terhadap drama adaptasi Korea Selatan iaitu 'Alamatnya Cinta' dengan menggunakan kaedah analisis tekstual, pengkaji mendapati bahawa sememangnya wujud pemaparan terhadap unsur kebudayaan Melayu melalui pemaparan kepada elemen agama Islam dan juga adat masyarakat Melayu yang telah dipersembahkan dengan baik oleh pembuat teks melalui adegan-adegan penyiarannya kepada audiens. Antara elemen pemaparan agama Islam yang hadir menerusi drama adaptasi ini adalah dari sudut perkahwinan dan penceraian, pemaparan masjid, pemakaian dalam Islam, penjagaan batas atara lelaki dan wanita, penggunaan simbol keagamaan serta adegan bersalaman. Manakala dari sudut adat melayu yang dipaparkan pula adalah dari segi adab membuka kasut di dalam rumah, amalan gadaian dalam kalangan masyarakat Melayu serta penggunaan status dalam kehidupan realiti sosial

\section{a. Pemaparan Agama Islam}

Setelah menonton semua 24 sampel episod dalam drama ini, kajian mendapati bahawa walaupun drama ini merupakan sebuah drama adaptasi daripada Korea Selatan, namun pembuat teks kepada drama ini sememangnya amat peka dengan memasukkan dan tetap menekankan ciri-ciri keislaman menerusi drama ini. Namun begitu, tidak kesemua episod mengandungi elemen pemaparan Islam dan hanya beberapa episod sahaja yang dilihat terdapatnya penonjolan kepada pemaparan elemen Islam dalam drama. Justeru itu dari aspek naratif, ruang keagamaan yang terdapat dalam kajian ini masih belum menyeluruh kerana masih terdapat beberapa adegan ajaran agama Islam yang tidak diikuti sepenuhnya, contohnya penutupan aurat dan penjagaan batas lelaki dan wanita.

Oleh itu selepas dianalisis, antara episod yang paling banyak mengetengahkan elemen Islam adalah di dalam episod ke-4 melalui pemaparan syot-syot kamera serta latar tempat yang disampaikan kepada penonton. Tambahan lagi, episod ini juga dilihat penting bagi keseluruhan peceritaan kerana di sinilah bermulanya titik perubahan bagi kehidupan watak utama iaitu Faliq dan Ellie untuk hidup bersama sebagai pasangan suami isteri kerana mereka bakal dinikahkah dalam episod ini. Disebabkan hal ini juga, banyak elemen keislaman diterapkan pada episod ini seperti acara pernikahan dalam Islam, etika pemakaian dalam perspektif Islam dan tempat beribadat bagi umat Islam.

Sebagai contoh, terdapat banyak pemaparan bagi elemen Islam yang muncul menerusi adegan pemaparan wanita berhijab bersama pemakaian telekung di hadapan masjid. Adegan ini juga pada asalnya menceritakan Faliq iaitu watak utama yang cuba melarikan diri kerana tidak mahu bernikah dan mengahwini Ellie dengan menggunakan telekung sembahyang wanita sebagai medium penyamaran. Justeru, di Malaysia telekung sememangnya sinonim digunakan bagi tujuan solat dan beribadat bagi wanita Islam terutamanya apabila pergi ke masjid untuk menunaikan ibadah. Selain telekung, kelihatan juga Ellie memakai penutup kepala (tudung) apabila berada di sekitar kawasan masjid. 
Menurut Rashidah Othman et al. (2016), pemakaian tudung dan juga menutup aurat merupakan kewajiban utama bagi setiap wanita Islam.

Pada dasarnya, Ellie bukanlah seorang wanita muslim yang memakai tudung dan menutup aurat di dalam drama adaptasi ini, namun pada adegan ini Ellie dilihat tetap menghormati agama Islam itu sendiri kerana memakai tudung dan menutup aurat apabila berada di Masjid dan kawasan sekitarnya. Ini juga sekaligus menunjukkan bahawa pembuat teks kepada karya adaptasi ini peka dan mengambil berat apabila melihatkan adegan yang mempunyai elemen keagamaan. Di samping itu, kelihatan juga pemilihan warna putih yang digunakan oleh Ellie dan juga telekung yang berwarna putih sebagai perlambangan kepada kesucian agama Islam itu sendiri. Ini sejajar dengan penyataan daripada Monika Abd Razzak et al. (2013) iaitu warna putih adalah antara warna yang menjadi lambang kepada kesucian dan kebersihan. Latar belakang adegan ini pula mempamerkan masjid dan sekaligus secara tidak langsung menyatakan lokasi kepada adegan terbabit adalah di sekitar kawasan masjid.

Selain itu, episod ini juga memaparkan banyak adegan di dalam masjid, sebagai contoh paparan adegan Faliq telah bersedia untuk dinikahkan di hadapan Tok Kadi dan para saksi. Hal ini juga dilihat sebagai satu refleksi kepada dunia realiti yang sememangnya masyarakat Melayu di Malaysia kebanyakannya memilih masjid sebagai lokasi ideal bagi melakukan upacara pernikahan (Mustari \& Jasmi, 2008). Di samping itu, dapat dilihat juga pemakaian songkok dan kopiah yang merupakan penutup kepala seorang lelaki Islam yang dipakai oleh Faliq dan kaum lelaki di dalam masjid tersebut. Menurut Asliza et al. (2015), songkok dan kopiah biasanya dipakai ketika hendak menunaikan solat atau ketika menghadiri majlis berbentuk keagamaan dan budaya.

Justeru itu, perkahwinan mahupun pernikahan adalah perkara yang amat mulia dalam Islam. Menurut Mariam dan Mohammad Syafirul (2017), perkahwinan merupakan suatu ikatan yang dijalinkan di antara pasangan suami dan isteri menerusi suatu akad. Perkahwinan juga merupakan lambang kehormatan dan kemuliaan bagi pasangan suami dan isteri serta dilakukan bagi mengelakkan daripada berlakunya pelbagai perkara yang tidak diingini seperti masalah sosial dan kes pembuangan bayi. Disebabkan hal inilah, dalam Islam seorang lelaki dan wanita yang bukan muhrim juga dilarang untuk berdua-duaan kerana memungkinkan pelbagai perkara negatif untuk berlaku amat tinggi.

Oleh itu, jika perkara ini berlaku dan dilaporkan kepada pihak autoriti, pelaku tersebut akan ditangkap dan juga didenda seperti yang dipaparkan menerusi drama 'Alamatnya Cinta' apabila gambar Faliq dan Ellie berdua-duaan tular di laman sosial. Menurut Ainul et al. (2012), khalwat bermaksud pengasingan diri di tempat-tempat yang tersembunyi oleh lelaki dan perempuan yang tidak berkahwin atau berada berdua-duaan di dalam keadaan yang mencurigakan di tempat-tempat yang terpencil di antara lelaki dan perempuan yang belum bernikah. Justeru itu, perkara ini amat dilarang sama sekali dalam agama Islam kerana memberikan keburukan kepada individu tersebut.

Rentetan itu, adegan ini juga dilihat sebagai satu refleksi dan mencerminkan keadaan sosial sebenar yang berlaku dalam ruang lingkup masyarakat tempatan. Susulan itu, melihat kepada drama 'Alamatnya Cinta' perkahwinan antara Faliq dan juga Ellie adalah jalan paling selamat untuk dilakukan kerana perkahwinan adalah perkara yang mulia dan halal di sisi Islam. Tambahan lagi, perkahwinan mereka berdua ini juga akan menyelamatkan karier Faliq yang tercemar disebabkan spekulasi negatif yang dibuat oleh wartawan dan netizen terhadap hubungan mereka sebelum ini. 
Antara contoh lain kepada ciri keislaman yang ditonjolkan dalam drama ini juga boleh dilihat menerusi simbol dan juga bingkai gambar. Sebagai contoh yang amat jelas adalah dalam episod 14 dan 15 melalui kalimah ayat berunsur Islam seperti 'Muhammad' dan 'Allah' dalam bahasa Arab di dinding rumah watak antagonis iaitu Jasmine. Walaupun Jasmine mengamalkan gaya hidup barat dan merupakan seorang pelakon yang popular dalam drama ini, namun elemen Islam tetap diterapkan dan ditonjolkan kepada khalayak. Hal ini menunjukkan bahawa agama merupakan satu perkara yang penting dan juga teras kehidupan tidak kira apa jua latar belakang dan kisah hidup seseorang. Justeru itu nilai agama yang tidak diambil berat oleh masyarakat barat seperti yang dinyatakan oleh Khairiah (2014) sememangnya tidak diikuti menerusi karakter Jasmine ini dengan kehadiran elemen bercirikan Islam menerusi pemaparan dalam drama adaptasi ini.

Selain itu, terdapat juga paparan adegan bersalaman terhadap orang yang lebih tua dalam episod 13 pada minit ke 29.33, apabila Ellie yang bersalaman dengan nenda ataupun nenek kepada Faliq. Oleh itu, dalam kalangan masyarakat Melayu khususnya, bersalaman merupakan antara elemen yang penting sebagai tanda hormat golongan yang lebih muda kepada orang yang lebih tua dan berusia. Selain itu, adegan ini juga menunjukkan bahawa keluarga Faliq masih tetap berpegang kepada adat dan budaya Melayu walaupun menjalani kehidupan mewah dan juga serba moden. Justeru, ini menunjukkan bahawa pembuat teks kepada drama adaptasi tempatan ini sememangnya melakukan tugasnya dengan baik dalam memastikan kesemua elemen kebudayaan Melayu dan Islam yang dipaparkan kepada khalayak adalah bersesuaian, tepat serta boleh dijadikan contoh kepada audiens. Perkara ini dilihat sejajar dengan apa yang dinyatakan oleh Al-Jazairiy (2010), yang mana perbuatan melakukan pengurangan terhadap ajaran Islam atau melakukan penambahan terhadapnya adalah haram di sisi agama.

Walaupun drama ini pada asasnya mengisahkan kehidupan yang berteraskan kemodenan, namun ciri-ciri dan nilai Islam seperti menghormati orang yang lebih berusia itu tetap ditonjolkan kepada umum di dalam kebanyakan adegan menerusi drama adaptasi tempatan ini. Oleh yang demikian, ini selari dengan apa yang dinyatakan oleh Nurul Huda (2015) bahawa bersalaman dan berjabat tangan adalah suatu amalan mulia yang disyariatkan dalam Islam serta ianya juga melambangkan simbol meliputi ikatan sebuah hubungan sosial, kekeluargaan dan sebagainya.

Di Malaysia, sikap menghormati orang yang lebih berusia dan toleransi adalah suatu perkara yang dianggap amat penting bagi mencerminkan adab ketimuran selain berperanan sebagai sebuah negara majmuk. Ini juga dilihat selari dengan pernyataan Noriati (2005) yang mana nilai menghormati orang yang lebih berusia ini telah disemai sejak kecil lagi dalam kalangan masyarakat Melayu dan diperkuatkan lagi dengan pengaruh Islam yang hadir.

Selain itu, tiada langsung pemaparan ciri-ciri agama lain yang wujud selain agama Islam menerusi drama ini. Mesej kelslaman yang dipaparkan dalam bentuk drama ini juga tidak terhad kepada mana-mana peringkat umur, masa, kumpulan mahupun bangsa tetapi boleh diterima oleh seluruh lapisan masyarakat (Muhammad Muhaimin \& Rosmawati, 2018). Ini juga dilihat sebagai satu usaha murni pembuat teks dalam memberi pengetahuan berkaitan Islam kepada masyarakat tempatan khususnya sebagai contoh apabila adanya adegan acara akad nikah dalam Islam dan juga proses penceraian Islam yang dipaparkan pada episod ke-19.

Adegan proses penceraian ini juga dipaparkan dengan agak terperinci kepada audiens yang menonton apabila tiada lagi wujud persefahaman di antara kedua-dua pasangan. Menerusi drama ini, kedua-dua watak utama iaitu Faliq dan Hana masing-masing dipaparkan 
dengan jelas menemui peguam syariah bagi menguruskan hal penceraian rumahtangga mereka apabila merasakan bahawa mereka patut berpisah dan membawa haluan masingmasing. Menurut Raihanah (2013), ketidaksefahaman yang sering berlaku di antara suami isteri menjadi salah satu sebab berlakunya sesebuah penceraian. Disebabkan itu, penceraian ini juga merupakan jalan akhir dan satu tindakan yang perlu bagi memberikan solusi untuk kedua-dua belah pihak.

\section{b. Pemaparan Adat Melayu}

Pemaparan bagi elemen adat dan budaya masyarakat Melayu sememangnya wujud di dalam drama adaptasi Korea Selatan 'Alamatnya Cinta' ini namun penonjolannya tidak sebanyak pemaparan bagi agama Islam yang dipamerkan oleh pembuat teks kepada khalayak. Lebih unik lagi apabila hasil kajian ini tidak menjumpai sebarang adat dan tradisi daripada budaya masyarakat lain di dalam drama ini termasuk budaya masyarakat Korea Selatan. Dalam pada itu, kajian turut mendapati bahawa tidak kesemua 24 episod drama memaparkan dan merangkumi budaya masyarakat Melayu. Hal ini disebabkan kerana pembuat teks ini lebih menonjolkan sentimen kemodenan dan kehidupan kota yang canggih dan membangun dengan penggunaan latar tempat yang moden sebagaimana penceritaan bagi karya asal drama ini. Namun begitu, ciri dan nilai kemelayuan itu masih tetap tersemat rapi dan dipersembahkan dengan baik oleh pembuat teks dalam drama adaptasi ini kepada audiens.

Oleh itu, antara contoh adegan yang memaparkan adat dan budaya masyarakat Melayu adalah menerusi episod ke 12 iaitu Ellie kelihatan membuka kasutnya untuk masuk ke dalam rumah. Ini jelas mencerminkan budaya ketimuran serta menjaga kebersihan yang diterapkan oleh kebanyakan masyarakat Asia. Hal ini juga dilihat selari dengan ajaran Islam itu sendiri yang sentiasa mengutamakan kebersihan. Menurut Mohamed Taib (2004), memakai kasut di dalam rumah adalah sebuah perlakuan yang tidak sopan bagi masyarakat Melayu kerana dianggap tidak bersih dan kotor. Ini juga dilihat selari dengan apa yang diperkatakan oleh Shida dan Badaruddin (2014) yang mana amalan membuka kasut sebelum masuk ke dalam rumah sudah menjadi adat dan amalan masyarakat Melayu sejak dari dahulu lagi.

Selain adegan membuka kasut, terdapat juga adegan Ellie pergi ke tempat pajak gadai untuk menggadaikan cincin miliknya di episod ke-3 kerana memerlukan wang dengan kadar segera. Menurut Nur Hidayatul dan Salbiah (2020), budaya pajak gadai dan menggadaikan barang kemas ini juga dilihat sudah sebati dalam diri masyarakat Melayu Islam yang akan menggunakan sistem gadaian ini apabila dalam keadaan yang terdesak dan memerlukan wang. Dalam pada itu gadaian ini juga merujuk satu proses pembiayaan jangka pendek yang memberi kemudahan kepada masyarakat bagi mendapatkan pembiayaan hutang secara cepat (Nadiah et al., 2015). Oleh itu, penggunaan adegan memajak barang kemas menerusi drama adaptasi ini juga dilihat sebagai satu cerminan yang memaparkan kondisi sebenar masyarakat Melayu di Malaysia.

Seterusnya, Malaysia merupakan antara negara yang mempunyai jurang kuasa yang tinggi di dalam kelompok masyarakatnya dan perkara ini sudah pun menjadi akar umbi serta adat dan amalan bagi masyarakat Melayu seperti yang dinyatakan oleh Mohd Suharta dan Ahmad (2018) terutama sekali dari sudut penggunaan gelaran dan pangkat yang diberikan kepada seseorang individu. Hal ini dapat dilihat dengan jelas sekali menerusi episod ke-3 apabila ibu kepada Jasmine menyuruh Emma, iaitu pengurus kepada Faliq, untuk memanggilnya dengan gelaran 'Datin'. 
Di Malaysia gelaran 'Datin' merupakan gelaran pangkat kepada isteri seseorang yang menyandang darjah kehormatan yang membawa gelaran 'Datuk' atau 'Dato' bergantung pada negeri yang memberikan darjah kehormat tersebut. Selain itu, gelaran 'Datin' juga boleh diberikan terus kepada seseorang wanita sebagai menghargai sumbangan beliau kepada negara, dengan tidak perlu berkahwin dengan seseorang yang bergelar 'Datuk' untuk mendapatkan gelaran 'Datin' tersebut. Justeru, ini sejajar dengan pernyataan Mohd Khairuddin et al. (2020) iaitu di Malaysia, perubahan dalam kelas sosial budaya orang Melayu banyak dipengaruhi oleh persekitaran dan kemajuan kelas sosial yang hadir pada zaman kini. Disebabkan hal ini, gelaran 'Datin' ini dilihat tinggi dalam kalangan masyarakat dan perlu dihormati di Malaysia. Justeru itulah ibu kepada Jasmine tetap menyuruh Emma memanggilnya 'Datin' bagi menunjukkan kuasa dan statusnya yang berbeza daripada masyarakat marhaen.

\section{PERBINCANGAN}

Apabila diteliti dan dilihat kepada kesemua 24 episod drama adaptasi Korea 'Alamatnya Cinta' ini, kajian merumuskan bahawa pemaparan terhadap agama Islam dan budaya Melayu itu masih dikekalkan di dalam drama ini. Hal ini boleh disimpulkan kerana drama ini merupakan sebuah drama adaptasi yang ditayangkan di Malaysia dan juga berbahasa Malaysia. Walaupun Malaysia merupakan sebuah negara berbilang kaum dan agama, namun agama rasminya tetap Islam dan Bahasa Malaysia merupakan bahasa kebangsaan (Hairuddin \& Che Asiah, 2008).

Disebabkan itu, drama ini masih menekankan unsur kelslaman dan keMelayuan di dalam drama ini disebabkan rata-rata sasaran penonton itu sendiri juga adalah masyarakat berbangsa Melayu. Ini selari dengan pernyataan Effendi (2004) bahawa adat yang sebenar adalah adat yang berdasar dan berpegang kepada ajaran agama Islam itu sendiri. Tambahan juga, dapat dilihat kepada barisan pelakon yang digunakan kesemuanya memegang watak sebagai seorang Melayu Islam dan ini mengukuhkan lagi terhadap penggunaan elemen Islam dan keMelayuan yang banyak menerusi pembikinan drama adaptasi ini. Walaupun kehadiran terhadap adat bagi masyarakat Melayu itu agak kurang dari sudut penonjolannya oleh pembuat teks, namun ianya sudah cukup mencerminkan situasi sebenar masyarakat Melayu moden di Malaysia.

Sebilangan besar adegan dalam drama ini juga dilakonkan di dalam rumah agam milik Ellie yang memegang watak utama. Hal ini menyebabkan pemaparan kepada budaya masyarakat Melayu itu lebih dipertontonkan kepada umum memandangkan Ellie sendiri adalah berbangsa Melayu. Rentetan itu, walaupun drama ini merupakan sebuah drama adaptasi dari Korea Selatan, namun kajian mendapati bahawa dari sudut pemaparan adat dan tradisi daripada Korea Selatan itu sememangnya tidak ditonjolkan langsung melainkan hanya ada sebuah babak yang mempunyai dialog terhadap mee 'ramyen' yang hendak dimakan oleh Faliq dalam episod ke 18.

Dalam siri asal 'Full House', watak utama bagi drama ini dipaparkan tinggal bersamasama dalam satu rumah tanpa ikatan yang sah. Namun begitu, dalam versi adaptasi 'Alamatnya Cinta' ini jelas kelihatan adegan tersebut tidak berlaku sebaliknya diubah mengikut acuan adat dan agama Islam itu sendiri iaitu mereka perlu berkahwin jika ingin tinggal serumah bersama-sama. Hal ini sedikit sebanyak dilihat memberikan pencerahan kepada masyarakat selain beragama Islam tentang agama Islam itu sendiri. Selain itu, pembuat teks kepada drama adaptasi ini juga dilihat bijak untuk mengolah adegan tersebut 
mengikut acuan budaya tempatan bagi mengelakkan timbulnya isu sensitiviti yang boleh merosakkan hubungan antara kaum di Malaysia khususnya.

Seterusnya, kajian mendapati bahawa keseluruhan drama ini pada dasarnya memaparkan sisi kemodenan dan kehidupan masyarakat bandar kerana kebanyakan adegan diambil di sekitar Kuala Lumpur. Lantaran itu, kebanyakan karakter yang muncul di dalam drama ini juga merupakan golongan elit, selebriti dan pereka fesyen. Hal seperti ini juga dilihat sebagai salah satu faktor penyumbang kepada sisi kehidupan modenisasi yang terlihat dalam karakter drama ini. Hal ini dapat dilihat dengan jelas dalam episod 6 iaitu Ellie menggunakan sudu di meja makan untuk menjamu selera bersama Faliq dan neneknya. Namun begitu, dalam adegan ini Ellie juga ditegur oleh Faliq supaya tidak berbual ketika makan kerana dilihat sebagai perbuatan yang kurang sopan sebagai orang Melayu. Ini membuktikan elemen keMelayuan tersebut tetap disemat oleh pembuat teks dan dipertontonkan kepada khalayak walaupun mereka hidup dalam kondisi yang serba mewah.

Selain itu, elemen pakaian juga dilihat lebih menjurus ke arah kehidupan moden serta pemakaian kepada baju kebangsaan seperti baju kurung dan juga baju Melayu hanya terlihat pada adegan di mahkamah syariah semasa kes penceraian dan di kawasan masjid sahaja. Hal ini juga termasuk kepada pemaparan bagi elemen Islam seperti pemakaian tudung juga hanya kelihatan pada adegan tertentu sahaja. Hal ini selari dengan pernyataan Norfaizah dan Zulkifli (2017) iaitu masyarakat Melayu kini sudah mula untuk menerima budaya lain yang telah berasimilasi ke dalam budaya Melayu kerana dasar keterbukaan yang diamalkan sejak dari zaman dahulu asalkan tidak mengganggu-gugat dan bertentangan dengan ajaran Islam.

\section{KESIMPULAN}

Kesimpulannya, hasil kajian terhadap drama ini mendapati walaupun drama ini merupakan drama adaptasi daripada Korea Selatan namun elemen kebudayaan masyarakat Melayu dan Islam itu masih dikekalkan dan dipertontonkan kepada masyarakat dengan baik dan jelas. Kajian juga percaya bahawa ini adalah suatu pendekatan yang harus dicontohi oleh kebanyakan pembuat teks dan drama untuk memperbanyakkan lagi penggunaan elemen budaya dan agama masyarakat di Malaysia lebih-lebih lagi untuk tontonan generasi muda supaya mereka lebih mengenali asal-usul serta budaya tradisi mereka menerusi kaca televisyen. Hal ini kerana televisyen merupakan saluran utama dan mampu mewujudkan suatu kebudayaan sebagai gambaran realiti sosial dari identiti sosial, gagasan, kepercayaan, dan juga nilai-nilai moral (McQuail, 2005).

Selain itu, Mohamad Zain dan Nik Hassan (2010) berpendapat budaya boleh dilihat dari pelbagai sudut dan salah satunya adalah peranannya dalam mempromosikan keamanan dan keharmonian antara pelbagai bangsa dan masyarakat. Malaysia merupakan sebuah negara yang berbilang kaum dan agama. Justeru itu dengan adanya drama yang memaparkan nilai budaya sesebuah komuniti ini sekaligus dapat memberikan pencambahan idea kepada bangsa lain tentang budaya yang dipersembahkan menerusi drama televisyen tersebut.

Melalui drama yang telah dianalisis ini, kajian mendapati cabaran globalisasi, kemasukan budaya popular mahupun moderniti sememangya tidak mempengaruhi pembuat teks bagi drama 'Alamatnya Cinta' ini untuk tidak meletakkan elemen kelslaman dan ciri keMelayuan di dalam drama ini. Hal ini sememangnya terbukti kerana terdapat banyak elemen Islam dan keMelayuan yang dipaparkan serta amat kurang penonjolan bagi pemaparan terhadap budaya lain dipertontonkan dalam drama ini. Oleh itu, kajian ini ingin mencadangkan supaya suatu bentuk analisis kepada audiens pula dijalankan bagi melihat 
kepada pembinaan makna dan penerimaan mereka terhadap drama dan juga program adaptasi Korea Selatan ini khususnya dalam kalangan remaja di Malaysia.

\section{BIODATA}

Nazra Aliff Nazri merupakan pelajar Doktof Falsafah di Pusat Kajian Media dan Komunikasi, Fakulti Sains Sosial dan Kemanusiaan, Universiti Kebangsaan Malaysia. Pengkhususan kajian beliau adalah berkaitan komunikasi antarabudaya. E-mel: nazraaliff@yahoo.com

Abdul Latiff Ahmad adalah Pensyarah Kanan di Pusat Kajian Media dan Komunikasi, Fakulti Sains Sosial dan Kemanusiaan, Universiti Kebangsaan Malaysia. Pengkhususan kajian beliau adalah berkaitan komunikasi antarabudaya. E-mel: alba@ukm.edu.my 


\section{RUJUKAN}

Ahmad Fauzi Mohd Ayub, Norhasni Zainal Abidin, \& Andi Suwirta. (2014). Hubungan antara penggunaan internet bermasalah umum dan kesunyian dalam kalangan pelajar sekolah menengah. Jurnal Kajian Pendidikan, 4(2), 189-200.

Ainul Bashirah Ismail, Zuliza Mohd Kusrin, \& Mat Noor Mat Zain. (2012). Kesalahan khalwat dan perbuatan tidak sopan dan hukumannya menurut Islam. Jurnal Hadhari, 4(2), 6588.

Al-Jazairiy, J. (2010). Tafsir maudhu'i 90 laluan mudah ke syurga (Vol. 1, Terj. Arsil Ibrahim. Kuala Lumpur: Blue-T Publication Sdn. Bhd.

Alftberg, A., \& Bengtsen, P. (2018). The sci-fi brain: Narratives in neuroscience and popular culture, culture unbound. The Unbound Brain, 10(1), 11-30. https://doi.org/10.3384/cu.2000.1525.1810111

Asliza Aris, Norwani Md. Nawawi, \& Saemah Yusof. (2015). Refleksi Islam dalam pakaian tradisional Melayu: Baju kurung. Seminar Antarabangsa Warisan dan Tamadun Melayu (ICOMHAC 2015).

Astro Awani. (2019). They even support Free Palestine' - PU Syed dikecam gara-gara gelar BTS Setan. Dicapai pada 30 Oktober 2019, dari https://www.astroawani.com/beritahiburan/they-even-support-free-palestine-pu-syed-dikecam-garagara-gelar-btssetan-206462

Nadiah Nabilah Baharum, Selamah Maamor, \& Aziza Othman. (2015). Examining the factors that influence customer's intention to use Ar-Rahnu at post office: A case study in Kedah. Journal of Islamic Economics, Banking and Finance, 11(4), 86-99.

Dominic, S. (2003). Popular culture: Pengantar menuju teori budaya populer. Yogyakarta: Bentang.

Effendy, T. (2004). Pemakaian ungkapan dalam upacara perkawinan orang Melayu. Yogyakarta: Balai Kajian dan Pengembangan Budaya Melayu.

Fatimah Muhd Shukri, \& Nur Afifah Vanitha Abdullah. (2018). Sepet (2005): Sebuah filem nasional Malaysia. Jurnal Komunikasi: Malaysian Journal of Communication, 34(2), 309-322.

Grondona, M. (2000). A cultural typology of economic development. In L. E. Harrison \& S. P. Huntington (Eds.), Culture matters: How values shape human progress. New York: Basic Books.

Hairuddin Megat Latif, \& Che Asiah Abdullah. (2018). Islam dalam perlembagaan Malaysia: Kewajarannya berdasarkan faktor kesultanan Melayu. Journal of Ethics, Legal and Governance, 4, 1-12.

Hasrul Hashim, \& Bahiyah Omar. (2011). Transformasi penyiaran televisyen melalui internet: Kajian perhubungan kepuasan terhadap pengguna remaja. Jurnal Komunikasi: Malaysian Journal of Communication, 27(1), 146-169.

Julina Tajul Ariffin Hassan Abu Bakar, \& Nor Hafezah Yusof. (2018). Culture in Korean drama towards influencing Malaysian audiences. International Journal of Innovative Research in Engineering and Management, 5.

Khairiah Mohd. Yassin. (2014). Hubungan budaya dan ilmu dari perspektif barat dan Islam. Jurnal MANU, 20, 25-5. 
Khairul Hafiz Noor Hissham, Mohd Anuar Ramli, Mohd Anuar, \& Syed Mohd Jefri. (2019). Analisis budaya popular dalam masyarakat Melayu dari perspektif hukum Islam. Perbentangan kertas di Conference: Minggu Terbuka Akademi Pengajian Islam Universiti Malaya 2019 (MiTA '19).

Kłoskowska, A. (1996). Kultury narodowe u korzeni. Poland: Wydawnictwo Naukowe PWN.

KOREA.net. (2016). K-drama masterpieces (3): 'Full House'. Dicapai pada 12 Mei 2019, dari http://www.korea.net/NewsFocus/Culture/view?articleld=140875

Kurt, I., \& Gok, H. (2015). Impact of technology on the perceptions of culture shock. Mevlana International Journal of Moral and Values Education (MIJMVE), 2(2), 21-28.

Labaš, D., \& Mihovilović, M. (2011). Mass media and the semiotics of popular culture. Journal Kroatologija, 2(1), 122-122.

Lakonawa, P. (2013). Agama \& pembentukan cara pandang serta perilaku hidup masyarakat. Humaniora, 4(2), 790-799.

Malaysia Kini. (2017). Peminat di KL berkumpul kenang mendiang Jong-hyun. Dicapai pada 29 Oktober 2019, dari https://www.malaysiakini.com/hiburan/406315

Mariam Abd. Majid, \& Mohammad Syafirul Zarif Saleh Hudin. (2017, September). Perceraian rumah tangga di negeri Selangor Darul Ehsan dan pendekatan menanganinya. E-Jurnal Penyelidikan dan Inovasi, 4(2), 285-303.

McQuail, D. (2005). McQuail's mass communication theory. London: Sage Publications.

Md Azalanshah Md Syed. (2019). K-pop, aspirasi kemodenan dan ketidakpatuhan strategik dalam kalangan wanita Melayu. Jurnal Komunikasi: Malaysian Journal of Communication, 35(2), 101-120.

Md Azalanshah Md Syed. (2015). Penontonan drama rantaian dalam kalangan wanita Melayu. Kuala Lumpur: Penerbit Universiti Malaya.

Mohd Daud Ali. (2002). Fenomena 'sempalan' keagamaan di PTU: Sebuah tantangan bagi pendidikan agama Islam. Dalam Fuaduddin, \& Cik Hasan Bisri (Eds.), Dinamika pemikiran Islam di perguruan tinggi. Ciputat: Logos.

Mohd Khairuddin Mohad Sallehuddin, Muhammad Ridhwan Sarifin, \& Mohamad Fauzi Sukimi. (2020). Konsumerisme dan kelas sosial dalam majlis perkahwinan masyarakat Melayu. Jurnal Akademika, Isu Khas 1.

Mohd Suharta, T. Z., \& Ahmad, A. L. B. (2018). Nilai dimensi budaya: Suatu kajian analisis kandungan ke atas filem pecah panggung Malaysia. Jurnal Wacana Sarjana, 2(1).

Mohamed Taib Osman. (2004). Adat resam masyarakat Melayu. Kuala Lumpur: Jabatan Perpaduan Negara dan Integrasi Nasional.

Mohamad Zain Musa, \&, Nik Hassan Shuhaimi Nik Abdul Rahman. (2010). Peranan budaya dalam mempromosikan keharmonian di Asia Tenggara. Jurnal Terjemahan Alam \& Tamadun Melayu, 1(2), 183-189.

Monika@ Munirah Abd Razzak, Nik Mohd Zaim Ab Rahim, Nur Asilah Ibrahim, \& Khadher Ahmad. (2013). International Journal on Quranic Research (IJQR), 3(4), 95-120.

Muhammad Khairul Hafiz Noor Hissham, Mohd Anuar Ramli, \& Syed Mohd Jeffri Syed Jaafar. (2019). Unsur kearifan tempatan dalam seni persembahan Melayu-Islam: Analisis dari perspektif hukum Islam. Jurnal Fiqh, 16(2), 321-352.

Muhammad Muhaimin Zainal Abidin, \& Rosmawati Mohamad Rasit. (2018). Analisis mesej dakwah dalam filem Munafik (2016). Jurnal Fikiran Masyarakat, 6(1).

Mustari, M. I. \& Jasmi, K. A. (2008). Fungsi dan peranan masjid dalam masyarakat Hadhari. Skudai, Johor Bahru: Universiti Teknologi Press. 
Naquiah Nahar Sahrunizam Sangi, Dharsigah A/P Baniear Salvam, Nurhidayu Rosli, \& Abdul Hafiz Abdullah. (2018). Impak negatif teknologi moden dalam kehidupan \& perkembangan kanak-kanak hingga usia remaja. International Journal of Islamic and Civilizational Studies, 5(1), 87-99.

Ngo Sheau Shi, \& Harith Baharudin. (2015). Pemaparan kepelbagaian budaya dan agama dalam filem Muallaf arahan Yasmin Ahmad. Wacana Seni Journal of Arts Discourse, 14.

Noriati A. Rashid. (2005). Nilai kesantunan dalam sosiobudaya masyarakat Melayu. Jurnal Pengajian Melayu, 15.

Norfaizah Ghazali, \& Zulkifli Mohamad. (2017). Pengaruh budaya dalam drama bisikan Malaya. Journal of Kesidang, 2, 1-17.

Nor Raudah Siren, Munirah Ab Razak, Aisyah Yap, \& Ummu Hani Abu Hassan. (2019). Nilai dalam budaya Melayu-Islam melalui filem animasi Upin Dan Ipin. Conference Proceeding ICONIMAD 2019 International Conference on Islam in Malay World IX.

Nur Hidayatul Solehah Osman, \& Salbiah Nur Shahrul Azmi. (2020). Persepsi masyarakat terhadap pajak gadai Islam (Ar Rahnu). The Journal of Muamalat and Islamic Finance Research, 17(1), 70-78.

Nurul Huda. (2015). Berjabat tangan dengan lawan jenis. Jurnal Substantia, 17(1).

Rybina, P. (2018). Film adaptation as the art of expansion: The visual poetics of Marleen Gorris' Mrs. Dalloway. Journal of English Literature, 5, 59-76.

Putri, L. D. (2017). Kekuatan teknologi dalam membentuk budaya populer. Jurnal Lontar, 4(3: September - Desember 2016).

Raihanah Abdullah. (2013). Wanita, perceraian dan mahkamah syariah dalam wanita dan perundangan Islam. Kuala Lumpur: Ilmiah Publisher.

Rashidah Othman, Siti Norlina Muhamad, Farahwahida Mohd Yusof, \& Muhammad Amir Wan Harun. (2016). Fesyen wanita menurut perspektif Islam dan kesannya terhadap kesejahteraan fizikal dan spiritual. Jurnal Sains Humanika, 8(3), 65-71.

Rosmawati Mohamad Rasit, \& Azimah Misrom. (2016). Analisis elemen patuh syariah dalam filem Nur Kasih The Movie 2011. Berdasarkan teori filem Ar-Risalah. Jurnal Komunikasi: Malaysian Journal of Communication, 32(1), 580-602.

Shida Irwana Omar, \& Badaruddin Mohamed. (2014). Amalan hospitaliti dalam masyarakat Melayu tradisional dan sekarang: Kajian kes - program Inap Desa Di Jalan Bharu. Pulau Pinang: Penerbit Universiti Sains Malaysia.

Sohana Abdul Hamid. (2016). Pengaruh media massa terhadap perubahan sosial masyarakat. Journal of Social Sciences and Humanities, Special Issue 1 (October 2016), 214-226.

Solahuddin Abdul Hamid. (2016). Islam dalam pembentukan pandangan semesta masyarakat Melayu. Jurnal Seri Alam, (12), 143-150.

Tian, M., Deng, P., Zhang, Y., \& Salmador, M. P. (2018). How does culture influence innovation? A systematic literature review. Management Decision, 56(5), 1088-1107.

Villano, B. D. (2012). Dramatic adaptation, authorship and cultural identity in the eighteenth century. The Case of Samuel Foote. Journal of Early Modern Studies, 1(1), 175-191.

Yusoff, W. F. W., \& Hamid, R. A. (2013). Pengaruh agama dan adat dalam penerimaan masyarakat Melayu di negeri-negeri Melayu Bersekutu terhadap perubatan barat sewaktu zaman penjajahan British. Penang: Penerbit Universiti Sains Malaysia.

Zainal Kling. (2004). Adat Melayu. Dalam Abdul Latiff Abu Bakar, \& Hanipah Hussin (Eds.), (2004). Kepimpinan adat perkawinan Melayu Melaka. Melaka: Institut Seni Malaysia Melaka. 